\title{
Lipoxin $\mathrm{A}_{4}$ impairment of apoptotic signaling in macrophages: implication of the PI3K/Akt and the ERK/Nrf-2 defense pathways
}

\author{
P Prieto ${ }^{1}$, J Cuenca ${ }^{1}$, PG Través ${ }^{1}$, M Fernández-Velasco ${ }^{1}$, P Martín-Sanz ${ }^{1,2}$ and L Boscáa, ${ }^{1,2}$
}

Lipoxin $\mathrm{A}_{4}\left(\mathrm{LXA}_{4}\right)$ is an endogenous lipid mediator that requires transcellular metabolic traffic for its synthesis. The targets of $\mathrm{LXA}_{4}$ on neutrophils are well described, contributing to attenuation of inflammation. However, effects of lipoxins on macrophage are less known, particularly the action of $\mathrm{LXA}_{4}$ on the regulation of apoptosis of these cells. Our data show that pretreatment of human or murine macrophages with $\mathrm{LXA}_{4}$ at the concentrations prevailing in the course of resolution of inflammation (nanomolar range) significantly inhibits the apoptosis induced by staurosporine, etoposide and S-nitrosoglutathione or by more pathophysiological stimuli, such as LPS/IFN $\gamma$ challenge. The release of mitochondrial mediators of apoptosis and the activation of caspases was abrogated in the presence of $\mathrm{LXA}_{4}$. In addition to this, the synthesis of reactive oxygen species induced by staurosporine was attenuated and antiapoptotic proteins of the Bcl-2 family accumulated in the presence of lipoxin. Analysis of the targets of $\mathrm{LXA}_{4}$ identified an early activation of the PI3K/Akt and ERK/Nrf-2 pathways, which was required for the observation of the antiapoptotic effects of $\mathrm{LXA}_{4}$. These data suggest that the $\mathrm{LXA}_{4}$, released after the recruitment of neutrophils to sites of inflammation, exerts a protective effect on macrophage viability that might contribute to a better resolution of inflammation. Cell Death and Differentiation (2010) 17, 1179-1188; doi:10.1038/cdd.2009.220; published online 22 January 2010

Regulation of apoptosis of immune cells is a critical stage during inflammation because when the injury is over, accomplishment of a correct resolution, mainly through apoptotic death, prevents the development of chronic inflammatory diseases. $^{1,2}$ During this process, neutrophils are quickly recruited to sites of infection at which they have a very short life and die rapidly through apoptosis. ${ }^{3}$ Macrophages arrive later to phagocytic apoptotic cells and pathogens in the affected area. Thus, for an effective resolution of the inflammatory process, it is important that macrophages have a sufficient life span to clear the inflamed area (2-3 days).

Lipoxins (LXs) are endogenous eicosanoids that are released during the resolution phase of inflammation, in the nanomolar range. ${ }^{4}$ Lipoxins are mainly generated by transcellular metabolism from arachidonic acid depending on the cellular context. 5,6 In mammals, lipoxygenase enzymes (LOXs) generate two main native products: lipoxin $A_{4}\left(L X A_{4}\right)$ and $B_{4}\left(L X B_{4}\right)$, with $L X A_{4}$ being the most studied, which exerts potent anti-inflammatory actions modulating leukocyte trafficking and promoting phagocytic clearance of apoptotic cells. ${ }^{7,8}$ The effects of LXs as lipid mediators with potent anti-inflammatory actions are well documented, but their role in apoptosis remains controversial. ${ }^{9}$ For instance, an apoptotic effect on fibroblasts after treatment with $\mathrm{LXA}_{4}$ at micromolar concentrations has been described, ${ }^{10}$ whereas it has been also reported that this compound inhibits peroxynitrite formation in leukocytes, ${ }^{11}$ reduces colonocyte apoptosis ${ }^{12}$ and promotes survival of retinal pigment epithelial cells. ${ }^{13}$ Therefore, the precise role of LXs as modulators of apoptosis remains elusive and seems to be dependent on the cell type and on the $\mathrm{LXA}_{4}$ concentration. Given the lack of studies regarding the role of $\mathrm{LXA}_{4}$ in macrophage apoptosis and considering the importance of this immune cell in inflammation, we have investigated the effect of native $L_{X A_{4}}$ on macrophage apoptosis using staurosporine, etoposide and GSNO as strong apoptosis inducers in many cell types, ${ }^{3,14,15}$ and LPS/IFN $\gamma$ challenge as a more pathophysiological condition. Our results show that concentrations of $L_{X A_{4}}$ in the nanomolar range prevent apoptosis in murine and human macrophages through a mechanism consistent with changes in the levels of apoptosis-related proteins, favoring an antiapoptotic environment, and a blockade of early apoptotic signaling, which involves the suppression of the release of mitochondria-dependent apoptotic mediators and caspases activation. Moreover, our data show that $L X$ treatment of macrophages promotes a rapid activation of the PI3K/Akt signaling that is relevant for protection against apoptosis, in agreement with a previous study describing upregulation of antiapoptotic genes by this pathway, such as $M c /-1 .^{16}$ In addition to this, treatment of macrophages with $\mathrm{LXA}_{4}$ induced ERK/Nrf-2 activation, with Nrf-2 being a transcription factor that regulates the expression of $c a$. 100 cytoprotective genes that share in common a sequence termed antioxidant response element (ARE), ${ }^{17,18}$ and contributes to the

\footnotetext{
${ }^{1}$ Instituto de Investigaciones Biomédicas Alberto Sols (Centro Mixto CSIC-UAM), Arturo Duperier 4, 28029 Madrid, Spain and ${ }^{2}$ Centro de Investigación Biomédica en Red de Enfermedades Hepáticas y Digestivas (Ciberehd), Barcelona, Spain

${ }^{*}$ Corresponding author: L Boscá, Fisiopatologia de los procesos inflamatorios, IIBM (CSIC-UAM), Arturo Duperier 4, Madrid, 28029, Spain. Tel: + 34914972747 ; Fax: + 34915854 401; E-mail: Ibosca@iib.uam.es

Keywords: lipoxin; macrophage; oxidative stress; nrf2

Abbreviations: $\mathrm{LXA}_{4}$, Lipoxin $\mathrm{A}_{4}$; LXs, Lipoxins; LOXs, lipoxygenase enzymes; SAA, serum amyloid A; ROS, reactive oxygen species; RNIs, reactive nitrogen intermediates

Received 28.8.09; revised 16.12.09; accepted 17.12.09; Edited by H-U Simon; published online 22.1.10
} 
antioxidant defense pathway in many cells. ${ }^{19,20}$ Activation of this pathway in macrophages by $L X A_{4}$ decreased staurosporine-induced apoptosis, without affecting the activity of JNK and p38 MAPKs.

\section{Results}

LXA $_{4}$ prevents stimuli-dependent apoptosis in macrophages. Preliminary studies in our laboratory suggested that $\mathrm{LXA}_{4}$ enhanced the viability of activated macrophages. Using staurosporine as a potent and broad inducer of apoptosis in mammalian cells, we evaluated the ability of LX to interfere with the apoptosis induced by this drug in macrophages. Incubation for $4 \mathrm{~h}$ of RAW 264.7 cells with staurosporine $(200 \mathrm{ng} / \mathrm{ml})$ increased the percentage of annexin V-positive cells by $38 \%$ (Figure 1a). Preincubation for $2 \mathrm{~h}$ of the cells with $\mathrm{LXA}_{4}$ in the range of concentrations found under inflammatory conditions resulted in a dosedependent inhibition of the pro-apoptotic effect of staurosporine $\left(E_{50}=250 \mathrm{nM}\right)$. This protective action of $\mathrm{LXA}_{4}$ was mediated, at least in part, through its receptor, as it was interfered after $1 \mathrm{~h}$ of incubation with $1 \mu \mathrm{M}$ BocPLP, a formyl peptide $L X$ receptor antagonist, ${ }^{23,24}$ and was specific for $L X A_{4}$, the 15-epi-LXA 4 derivative being less effective (Figure 1a). Figure $1 \mathrm{~b}$ shows a representative flow cytometry distribution of this annexin $V$ analysis. The protective effect of LX against apoptosis was confirmed by DNA size distribution analysis, observing a significant reduction of the hypodipliod population (Figure 1c). When apoptosis was induced with
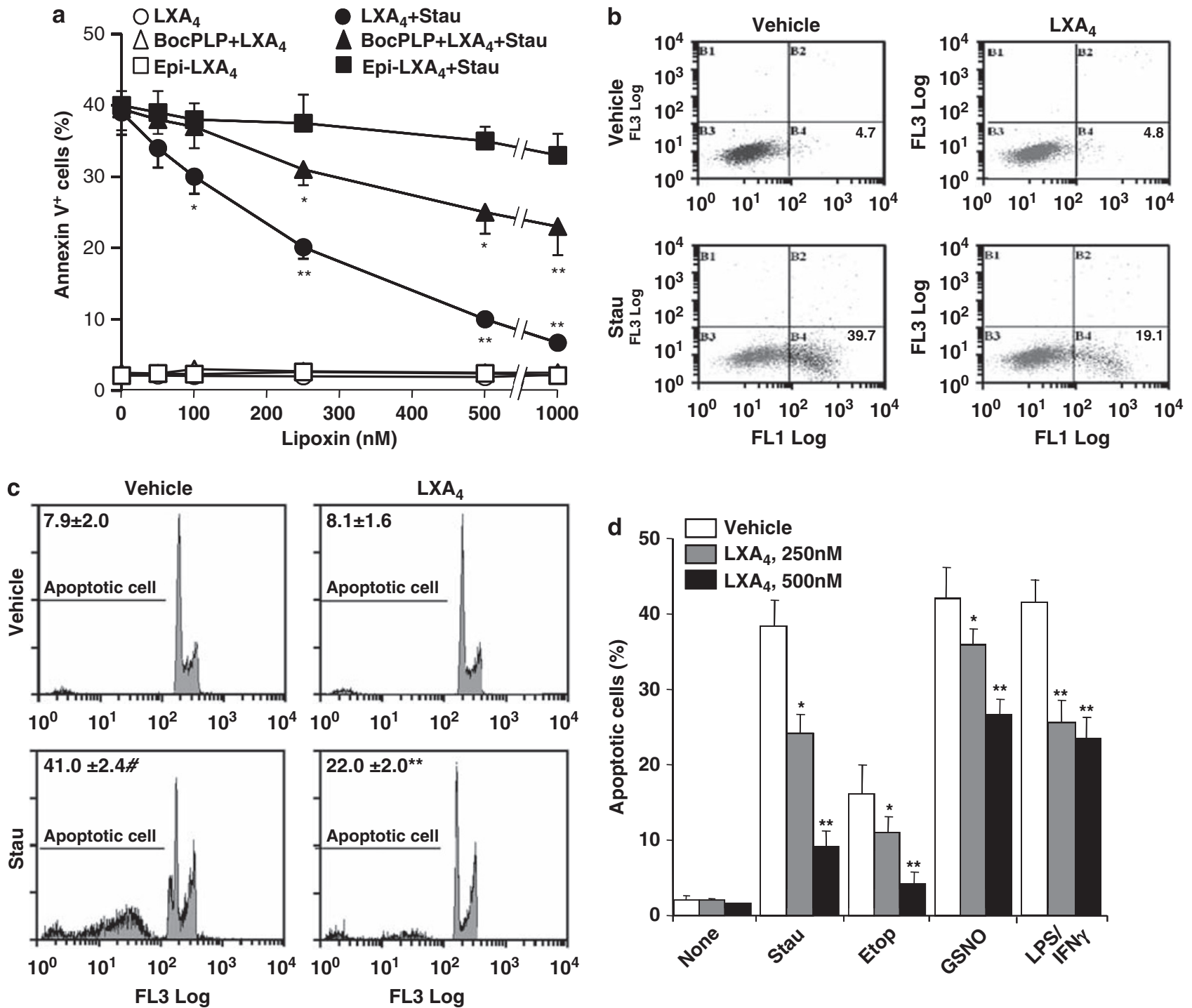

Figure 1 Lipoxin $\mathrm{A}_{4}$ attenuates apoptosis in RAW 264.7 cells. The percentage of annexin V-positive cells was determined by flow cytometry after preincubation ( $2 \mathrm{~h}$ ) of macrophages with the indicated concentrations of epi-LXA or $L X A_{4}$ in the absence or presence of $1 \mu M$ BocPLP (1 h before $L X A_{4}$ treatment), a lipoxin receptor antagonist, followed by apoptosis induction using $200 \mathrm{ng} / \mathrm{ml}$ of staurosporine or vehicle for $4 \mathrm{~h}$ (a). Representative dot plot diagrams are shown (250 $\mathrm{nM}$ of $\left.L X A_{4}\right)(\mathbf{b})$. This cell population was also analyzed by flow cytometry for nuclear DNA content (c). Cells were incubated with staurosporine (200 ng/ml), etoposide ( $1 \mu \mathrm{M})$ or GSNO $(0.5 \mathrm{mM})$ alone or in combination with LXA for $18 \mathrm{~h}$, and with LPS $(500 \mathrm{ng} / \mathrm{ml}) / \mathrm{IFN} \gamma(20 \mathrm{ng} / \mathrm{ml})$ for $48 \mathrm{~h}$. Apoptosis was determined by flow cytometry using PI labeling (d). Results show the mean \pm S.D. values of four different experiments. ${ }^{*} P<0.05$, ${ }^{*} P<0.01$ versus the corresponding condition in the absence of lipoxin 
etoposide $(1 \mu \mathrm{M})$, GSNO $(0.5 \mathrm{mM})$ or after LPS $(500 \mathrm{ng} / \mathrm{ml}) /$ IFN $\gamma \quad(20 \mathrm{ng} / \mathrm{ml})$ challenge, treatment of cells with $\mathrm{LXA}_{4}$ significantly decreased the apoptotic response in all these cases, suggesting the interference with a common pro-apoptotic signaling step (Figure 1d).

LX inhibition of caspase activation and pro-apoptotic signaling in macrophages treated with staurosporine.

To study the antiapoptotic effect of LX, the activation of caspases 3,8 and 9 was analyzed in cells treated with staurosporine. As shown in Figure $2 \mathrm{a}$, the well-known activation of caspases induced after staurosporine treatment $(200 \mathrm{ng} / \mathrm{ml} ; 4 \mathrm{~h}$ and $18 \mathrm{~h}$, respectively) was significantly impaired in the presence of $\mathrm{LXA}_{4}$. In addition to these determinations, the 'in vivo' activation of caspases was measured using cell-permeant fluorescent probes (representative example for caspase 3; Figure $2 b$, left panel). Figure $2 \mathrm{~b}$ (right panel) shows the percentage of cells with activated caspases 3,8 or 9 after staurosporine treatment. Lipoxin $A_{4}$ significantly reduced the percentage of cells with activated caspases, an effect that was in the range of that observed in cells treated with the broad caspase inhibitor z-VAD $(20 \mu \mathrm{M})$.
In view of these data, the release of pro-apoptotic mediators from the mitochondria was investigated because this is one of the key events in the commitment of the apoptotic response of macrophages. As shown in Figure 3, the release of cytochrome $c$ (panel A) and apoptosis-inducing factor (AIF; panel $B$ ) induced after staurosporine challenge was inhibited in LX-pretreated cells, and both proteins were retained in the mitochondrial/particulate compartment. In addition to this, the oxidative stress induced by staurosporine in macrophages was also attenuated after $L X$ treatment, as reflected by the decrease in DCFH oxidation in the presence of $\mathrm{LXA}_{4}$ (Figure $3 c$ ). Moreover, on using DAF-2 as RNI scavenger, a dose-dependent decrease in the oxidation of this probe, promoted by staurosporine, was observed in cells pretreated with LX (Figure 3d).

To investigate the mechanisms mediating the antiapoptotic effects of $\mathrm{LXA}_{4}$ in macrophages, the levels of apoptosisrelated proteins were determined by western blotting. As shown in Figure $4 \mathrm{a}$, treatment with $\mathrm{LXA}_{4}$ increased the levels of the antiapoptotic proteins, Mcl-1, and to a lesser extent those of $\mathrm{x}$-IAP and Bcl-2, without affecting the Bax levels on staurosporine challenge. Indeed, the ratio between $\mathrm{Mcl}-1$ (and also $\mathrm{x}-\mathrm{IAP}$ and $\mathrm{Bcl}-2$ ) and Bax (Figure $4 \mathrm{~b}$ ) well-reflected the protection against apoptosis observed in LX-treated cells.
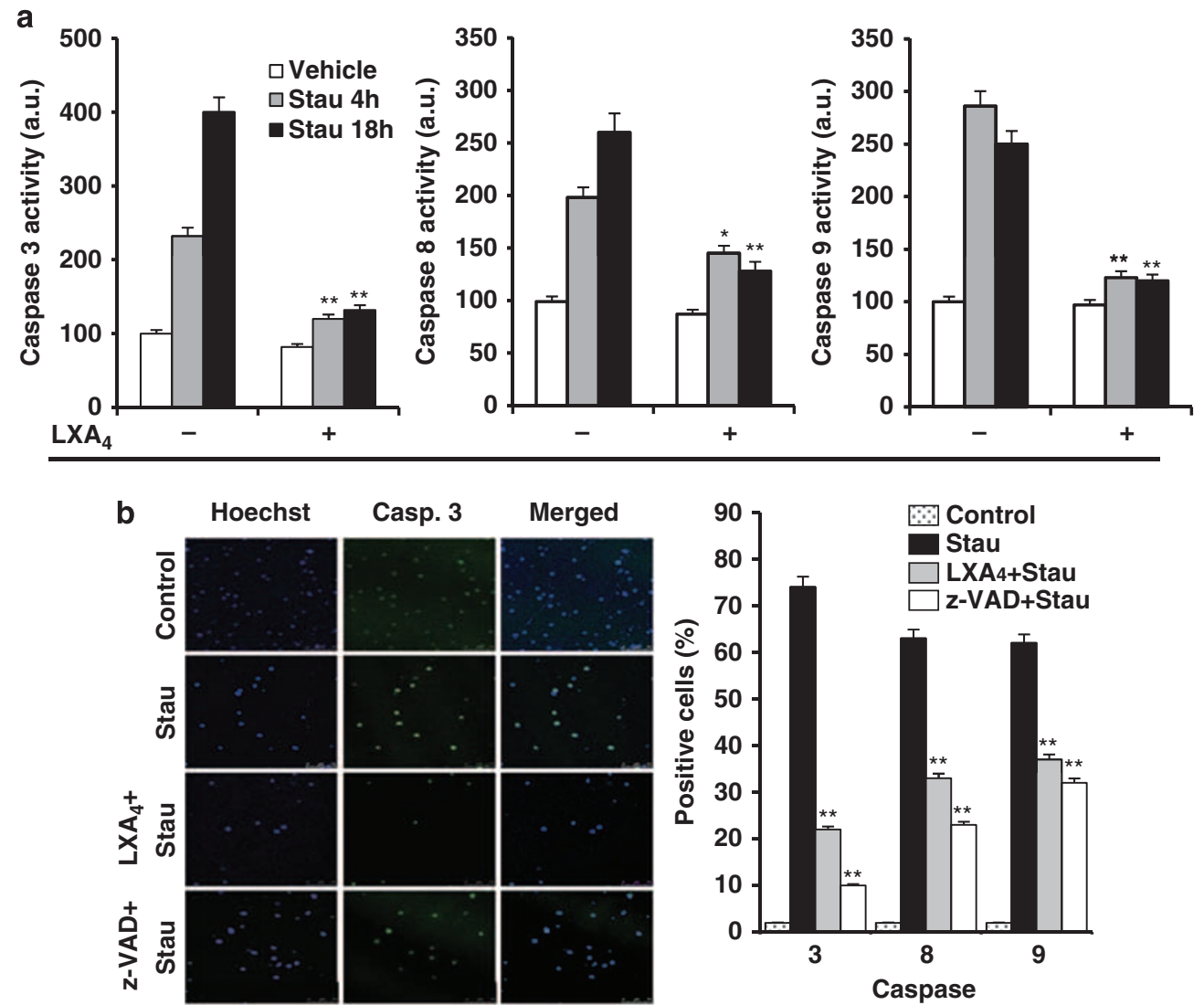

Figure 2 Lipoxin treatment impairs caspase activation in RAW 264.7 cells. Cells were treated for 4 or $18 \mathrm{~h}$ with $200 \mathrm{ng} / \mathrm{ml}$ staurosporine alone or in combination with $250 \mathrm{nM} \mathrm{LXA}_{4}$ (2-h pretreatment) and the activity of caspases 3, 8 and 9 was determined in cell extracts (a) or using CaspGlow 'in-cell' caspase activation detection (b; left panel: representative images of caspase 3-positive cells). The intensity of the cell fluorescence was digitalized and quantified with respect to the total cell number determined by Hoechst labeling (b, right panel). The broad apoptosis inhibitor z-VAD was used at $20 \mu \mathrm{M}$ following manufacturer's instructions as positive control. Results show the mean \pm S.D. values of three different experiments. ${ }^{*} P<0.05,{ }^{\star *} P<0.01$ versus the corresponding condition in the absence of lipoxin 
a

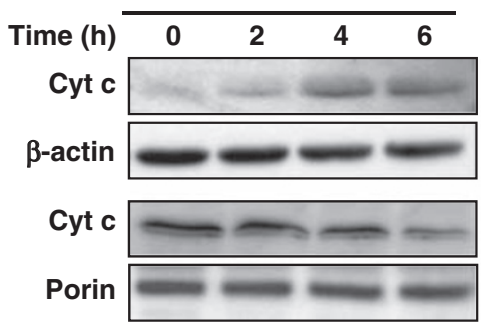

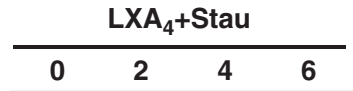

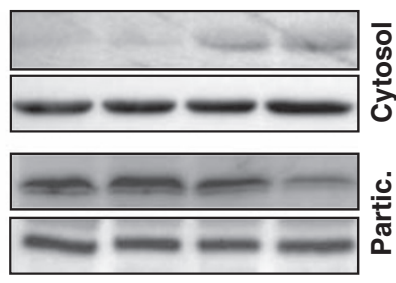

b
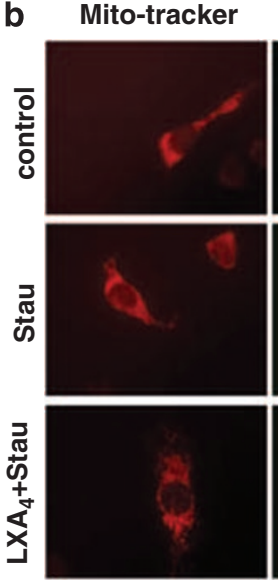

AIF
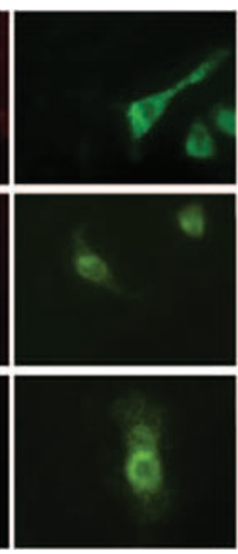

Merged
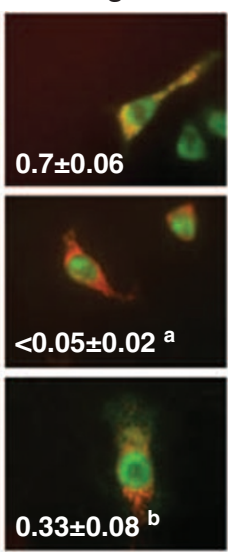
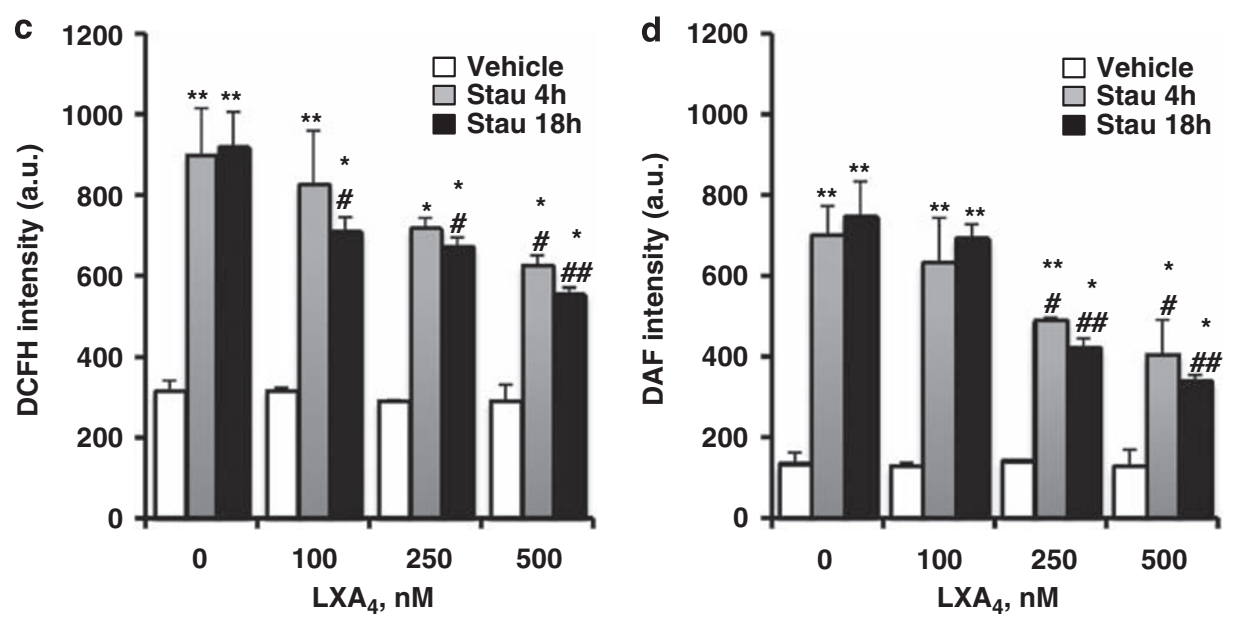

Figure 3 Release of mitochondrial apoptotic mediators and oxidative stress were reduced by lipoxin treatment in RAW 264.7. Cells were pretreated for $2 \mathrm{~h}$ with $\mathrm{LXA}$ $(250 \mathrm{nM})$ and challenged with $200 \mathrm{ng} / \mathrm{ml}$ of staurosporine for the indicated periods of time. Particulate (containing mitochondria) and cytosolic fractions of the cells were prepared and cytochrome $c$ levels were determined by Western blot using specific antibodies and $\beta$-actin (cytosol) and porin (mitochondria) as loading controls (a). The subcellular distribution of AIF was determined $4 \mathrm{~h}$ after staurosporine addition by confocal microscopy, as described in (a). Images were analyzed to determine the co-localization of mitochondrial markers and AIF and the ratio of 'green' (AIF) in 'red' (mito-tracker) of 60-80 cells per condition was quantified (b). To measure ROS production, macrophages were treated with the indicated stimuli, followed by loading with DCFH for 30 min at $37^{\circ} \mathrm{C}$ and its oxidation was monitorized by flow cytometry (c). Using the same treatment, cells were loaded with DAF-2 for $30 \mathrm{~min}$ at $37^{\circ} \mathrm{C}$ and its oxidation was determined to measure RNI production (d). Data are presented as mean \pm S.D. values of three different experiments or a representative blot (a) or cell image (b). ${ }^{a} P<0.01$ versus control, ${ }^{b} P<0.01$ versus the staurosporine condition (b). ${ }^{\star} P<0.05,{ }^{*} P<0.01$ versus vehicle-treated cells; ${ }^{\#} P<0.05,{ }^{\# \#} P<0.01$ versus the corresponding condition in the absence of lipoxin

To gain further insight into the differential apoptotic response of staurosporine-treated and LX-pretreated cells, we used a specific mouse apoptosis microarray to compare the gene expression profile after these treatments. Figure 4c summarizes the changes in the expression of genes, transcription of which is up/down by two-folds over the threshold value, among the apoptosis-related genes analyzed. Data show that staurosporine did not significantly alter the expression of the majority of the genes analyzed $(P<0.01)$. Moreover, using RT-PCR to confirm the array data, it was observed that, over the genes modified by staurosporine, $\mathrm{LXA}_{4}$ was able to significantly reduce the expression of some genes, such as $I L-10$ (Figure 4d), that promote a pro-apoptotic activity in macrophages. ${ }^{25}$ Indeed, LX did not significantly alter the expression of most of the genes involved in staurosporine-induced apoptosis, suggesting the involvement of post-transcriptional mechanisms in its mechanism of action.
LX-dependent survival involves AKT and ERK activation. The rise in Mcl-1 levels after $\mathrm{LXA}_{4}$ treatment suggests the activation of the PI3K/Akt pathway. ${ }^{16}$ As shown in Figure $5 \mathrm{a}, \mathrm{LXA}_{4}$ promoted a rapid Akt phosphorylation in a PI3K-dependent manner, as deduced by the inhibitory effect observed by LY294002 incubation. In addition to this and as MAPKs have been implicated in the regulation of basic cellular processes, such as apoptosis, survival, proliferation and differentiation, and our preceding data that suggest that $\mathrm{LXA}_{4}$ influences signaling steps upstream mitochondrial proapoptotic targeting, the effects of LX on the activity of these kinases were investigated. As illustrated in Figure $5 \mathrm{~b}$ and $\mathrm{c}$, staurosporine induced the phosphorylation of p38 and JNK from 30 to $120 \mathrm{~min}$; however, this treatment did not activate ERK over its low basal level. Pretreatment with $L X A_{4}$ did not affect p38 or JNK phosphorylation, but promoted a rapid activation of ERK after staurosporine challenge. Inhibition of 


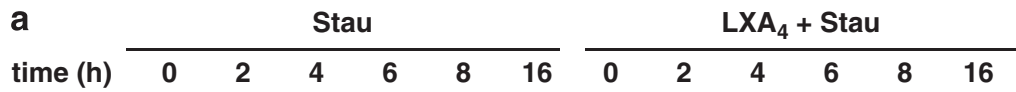
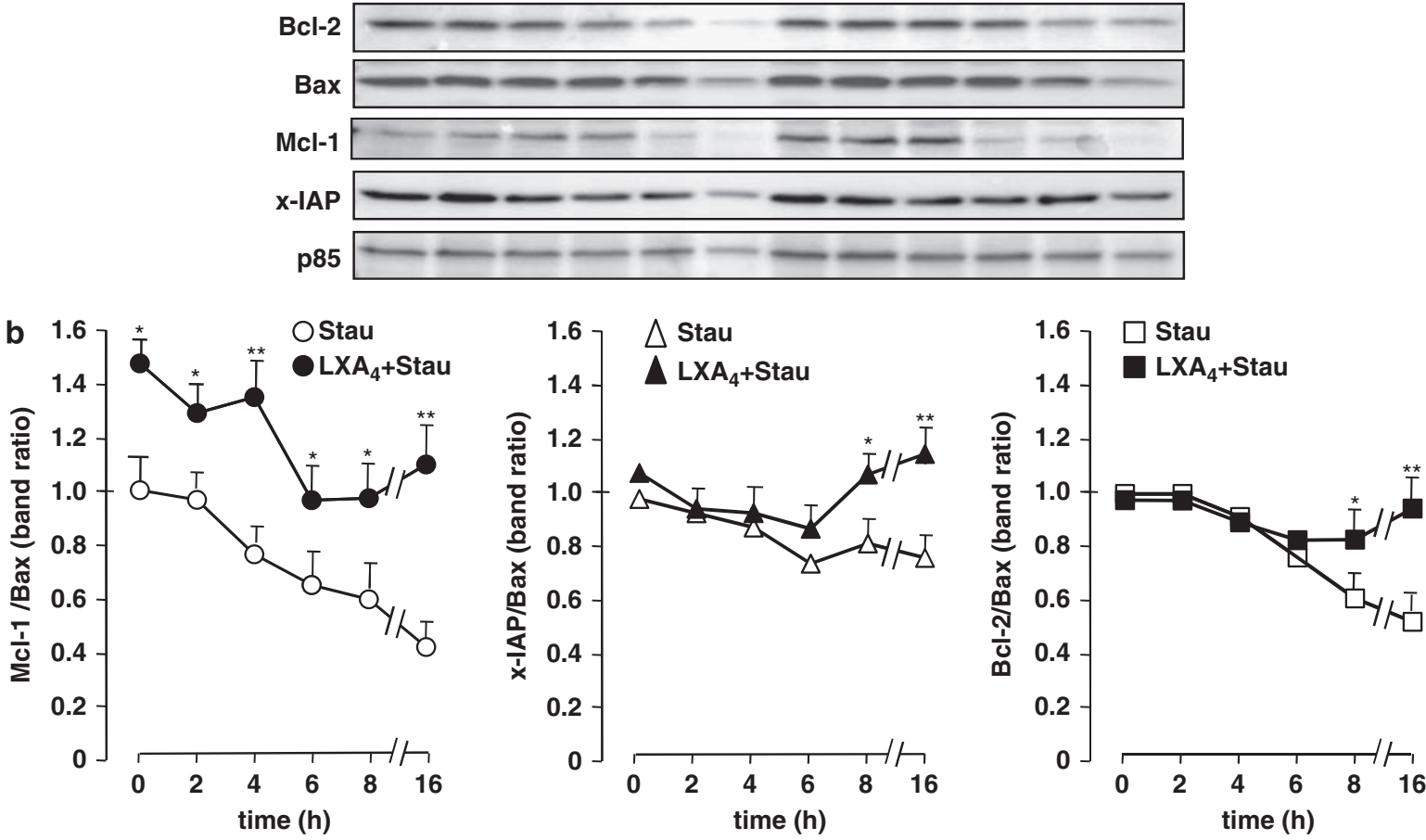

C $<-10 \quad 0 \quad>10$

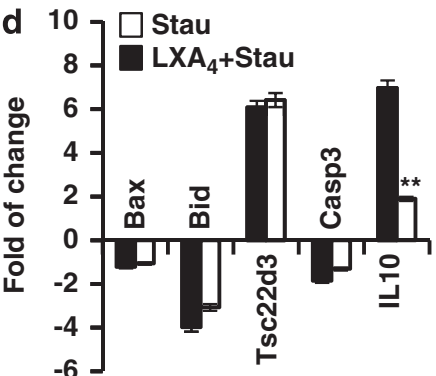

Figure 4 Changes of apoptotic-related genes and proteins in lipoxin-treated cells. RAW 264.7 cells were incubated with staurosporine $(200 \mathrm{ng} / \mathrm{ml})$ and $\mathrm{LXA} 4(250 \mathrm{nM})$ and analyzed at the indicated times. The protein levels of Bcl-2, Bax, Mcl-1 and X-IAP were determined by western blot. The levels of the p85 subunit of the PI3K were used as control for lane charge (a). After densitometric analysis, the ratios between Mcl-1, x-IAP and Bcl-2 versus Bax were calculated (b). Total RNA was analyzed using the Profiler PCR Array System and the SYBR Green/Fluorescein qPCR master mix (SuperArray Bioscience) and gene expression was compared with the web-based software package for the PCR Array System (http://www.superarray.com/pcr/arrayanalysis.php). Colorimetric diagram with a selection of the apoptosis-related genes analyzed: genes transcription of which is up/down (red/green) by two-fold in gene expression after staurosporine or lipoxin plus staurosporine treatment versus control (4h) is shown (c). RT-PCR of specific genes of the array was used to validate the data (d). Results show a representative blot $(n=3$; panel a) and the mean \pm S.D. value of band ratios. ${ }^{\star} P<0.05 ;{ }^{\star *} P<0.01$ versus the corresponding condition in the absence of lipoxin

this ERK activation using PD098059 $(1 \mu \mathrm{M})$ or PI3K activity using LY294002 $(10 \mu \mathrm{M})$ abolished the protective effect exerted by $L_{X A}$ against apoptosis (Figure $5 d$ ). In addition to this, the translocation to the nucleus and activation of the transcription factor Nrf-2 was also observed in $\mathrm{LXA}_{4}$ pretreated cells following kinetics similar to that of ERK activation (Figure 5e). Interestingly, unlike staurosporine, $\mathrm{LXA}_{4}$ was able to activate an ARE-luciferase reporter gene on transfection, whereas ERK inhibitor, PD098059, impaired this response, suggesting that the cytoprotective pathway dependent on Nrf-2 activity ${ }^{17,18}$ is activated in response to $\mathrm{LXA}_{4}$. MG132 was used as a positive control of ARE activation (Figure 5f). Finally, on using peritoneal macrophages from Nrf-2-deficient mice (Figure $5 \mathrm{~g}$ ), a significant decrease was observed in the antiapoptotic activity mediated by $\mathrm{LXA}_{4}$. Taken together, these data suggest a link between Akt and ERK/Nrf-2 activation and the protective effects against apoptosis exerted by $L X A_{4}$ in macrophages.

\section{Protection from apoptosis by $\mathrm{LXA}_{4}$ of murine and human} macrophages. To validate the results obtained in RAW 264.7 cells in other sources of macrophages, we carried out some key experiments in murine peritoneal macrophages. As shown in Figure $6 a$, the treatment with $L X$ promoted a rapid Akt phosphorylation in these cells that was inhibited in the presence of LY294002. Following the same line, challenge with staurosporine produced a rise in the phospho-ERK levels 
a

\begin{tabular}{|c|c|c|c|c|c|}
\hline \multicolumn{5}{|c|}{$\mathrm{LXA}_{4}, 250 \mathrm{nM}$} & \multirow[b]{2}{*}{ LY294002 } \\
\hline- & - & - & $\begin{array}{c}- \\
\end{array}$ & + & \\
\hline 0 & 2 & 5 & 10 & 1 & $(\min )$ \\
\hline \multicolumn{5}{|c|}{$-\infty-$} & P-Akt \\
\hline & & & & & Akt \\
\hline
\end{tabular}

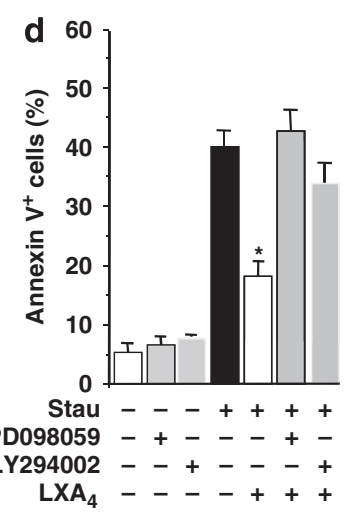

e $\frac{\text { Nuclear fraction }}{\text { Stau }} \frac{\text { LXA }_{4}+\text { Stau }}{0.50}$

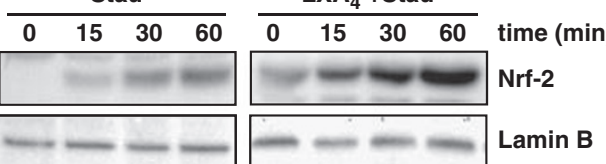

b

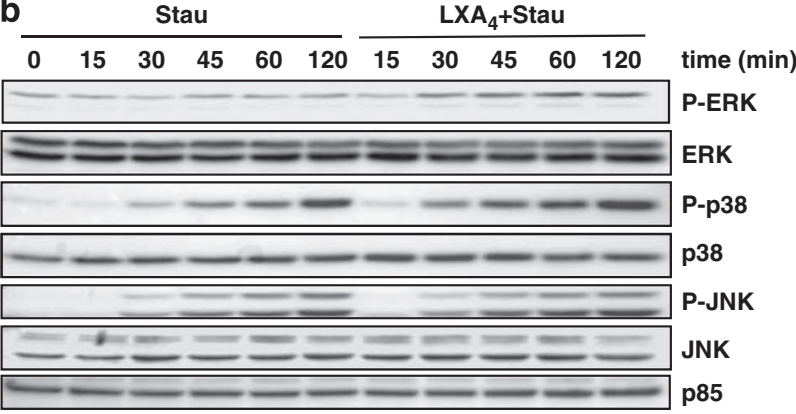

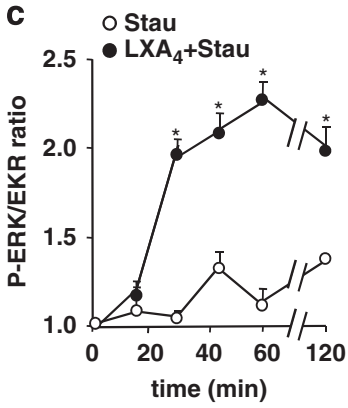
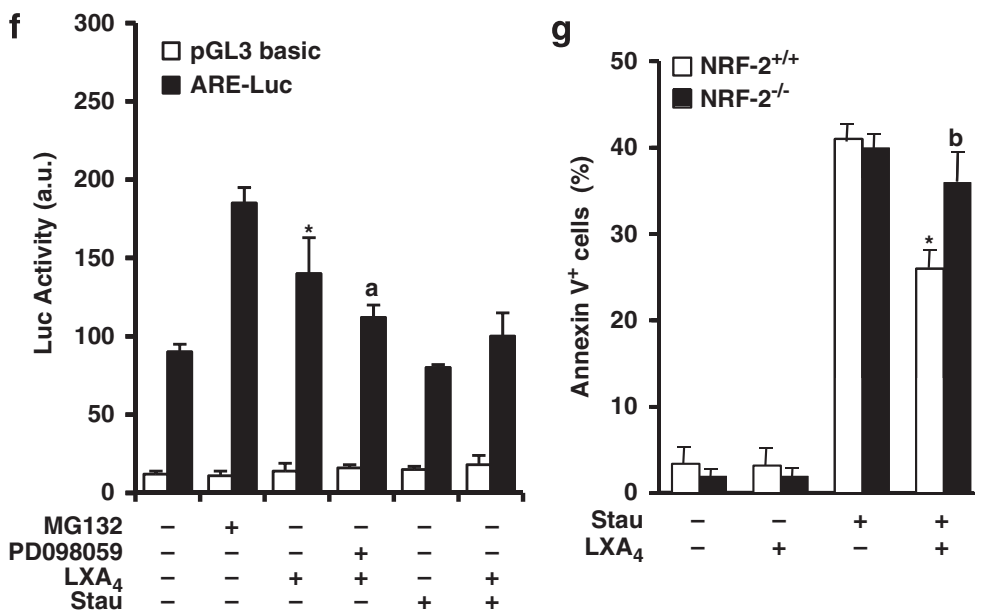

Figure $5 \mathrm{LXA}_{4}$ attenuation of macrophage apoptosis involves Akt and ERK/Nrf-2 activation. Cells were treated as described in Figure 1 and the phosphorylation of Akt in S473 was analyzed after LXA 4 challenge. Pretreatment with $20 \mu \mathrm{M}$ of the PI3K inhibitor, LY294002, inhibited Akt phosphorylation (a). The activity of the MAP kinases was followed by western blot analysis using specific antibodies (b); the pERK/ERK band ratio was calculated (c). Inhibition of PI3K with $10 \mu \mathrm{M} \mathrm{LY294002} \mathrm{(30} \mathrm{min} \mathrm{preincubation)} \mathrm{or}$ ERK with $1 \mu \mathrm{M}$ PD098059 (30 min preincubation) abrogated the LXA -dependent protection against apoptosis (d). Concomitant to ERK activation, Nrf-2 translocated to the nucleus (e) and the activity was increased by MG132 (20 $\mu \mathrm{M}$; used as positive control) and by LXA luc reporter vector (f). LXA $\mathrm{L}_{4}$ protection from staurosporine-induced apoptosis in peritoneal macrophages was attenuated in cells from animals lacking Nrf-2 (g). Data are presented as means \pm S.D. values of four different experiments. ${ }^{*} P<0.01$ versus the corresponding condition in the absence of lipoxin; ${ }^{\mathrm{a}} P<0.05$ versus the corresponding condition in the absence of PD098059 (f) $;{ }^{\mathrm{b}} P<0.01$ versus the corresponding value in Nrf-2 ${ }^{+1+}$ macrophages $(\mathbf{g})$

in cells treated with $L X$, a receptor-mediated effect, as it disappeared when these macrophages were pretreated with BocPLP before LXA 4 challenge (Figure 6b). As in RAW 264.7 cells, apoptosis was significantly prevented in $\mathrm{LXA}_{4}$-pretreated cells after stimulation with staurosporine, LPS/IFN $\gamma$ or the antimouse FAS Jo2. In agreement with our previous data, inhibition of the ERK or PI3K pathway attenuated the antiapoptotic effect exerted by LX (Figure 6c). To extend our results, we corroborated that similar effects in terms of apoptosis protection against staurosporine were obtained in cultured human monocyte/macrophages and in the monocytic cell line THP-1. These effects were also mediated by the Akt and ERK pathways as demonstrated using the corresponding inhibitors (Figure $6 \mathrm{~d}$ ). Lipoxin $\mathrm{A}_{4}$ also promoted the translocation of Nrf-2 to the nucleus in these cells as shown in Figure 6 e, thereby being capable to maintain the antiapoptotic effects previously reported in murine macrophages.

\section{Discussion}

This study provides evidence for a new mechanism of action of $\mathrm{LXA}_{4}$ by which this compound contributes to inflammation resolution, delaying the apoptosis in murine and human macrophages. Prolonged macrophage survival is required for phagocytosis of death cells in the inflamed area, avoiding excessive accumulation of cellular debris into the injured tissues. Lipoxins are natural compounds detected in several tissues in the nanomolar range, but exhibiting a certain cell specificity. In this regard, LXs have been involved in the pathogenic mechanism of some microbes. For example, in addition to the antiapoptotic effects of $\mathrm{LXA}_{4}$, it has been described that this LX prevents $P G E_{2}$ synthesis and this strategy is used by virulent Mycobacterium tuberculosis strains to avoid repair of the macrophage plasma membrane and to promote necrosis at the time the pathogen evades macrophage function. ${ }^{8}$ Therefore, although their role as antiinflammatory compounds is well documented, their implication in apoptosis has been a matter of debate. ${ }^{1,3,5,26}$ Opposite actions of $L X s$ on the balance between survival and apoptosis have been reported in neutrophils when signaling through the pleiotropic formylpeptide receptor like-1/LXA receptor. $^{23}$ This receptor binds a series of molecules, including $L_{X A}$, acute-phase reactant serum amyloid $A$ (SAA) and the glucocorticoid-inducible protein annexin-1. Although annexin 1 and LXs accelerate resolution/apoptotic death of neutrophils through caspase 3 activation, SAA rescues the cells by 


\begin{tabular}{|c|c|c|c|c|c|c|c|c|c|c|c|c|c|c|c|}
\hline \multicolumn{4}{|c|}{$\mathrm{LXA}_{4}$} & \multirow[b]{2}{*}{$\begin{array}{l}\text { LY294002 } \\
(\min )\end{array}$} & \multicolumn{4}{|c|}{ None } & \multicolumn{3}{|c|}{$\mathrm{LXA}_{4}$} & \multicolumn{3}{|c|}{ BocPLP+LXA } & \multirow[b]{2}{*}{$(\min )$} \\
\hline$\frac{-}{0}$ & - & $\frac{-}{5}$ & $\begin{array}{l}+ \\
5\end{array}$ & & 0 & 15 & 30 & 60 & 15 & 30 & 60 & 15 & 30 & 60 & \\
\hline & - & - & & P-Akt & & 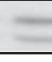 & 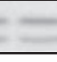 & & $=$ & - & $=$ & & $\square$ & - & $-I^{\prime}$ \\
\hline & & 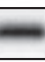 & & Akt & & & $=$ & $\equiv$ & $\equiv$ & $=$ & $=$ & $=$ & $=$ & $=$ & ERK \\
\hline
\end{tabular}
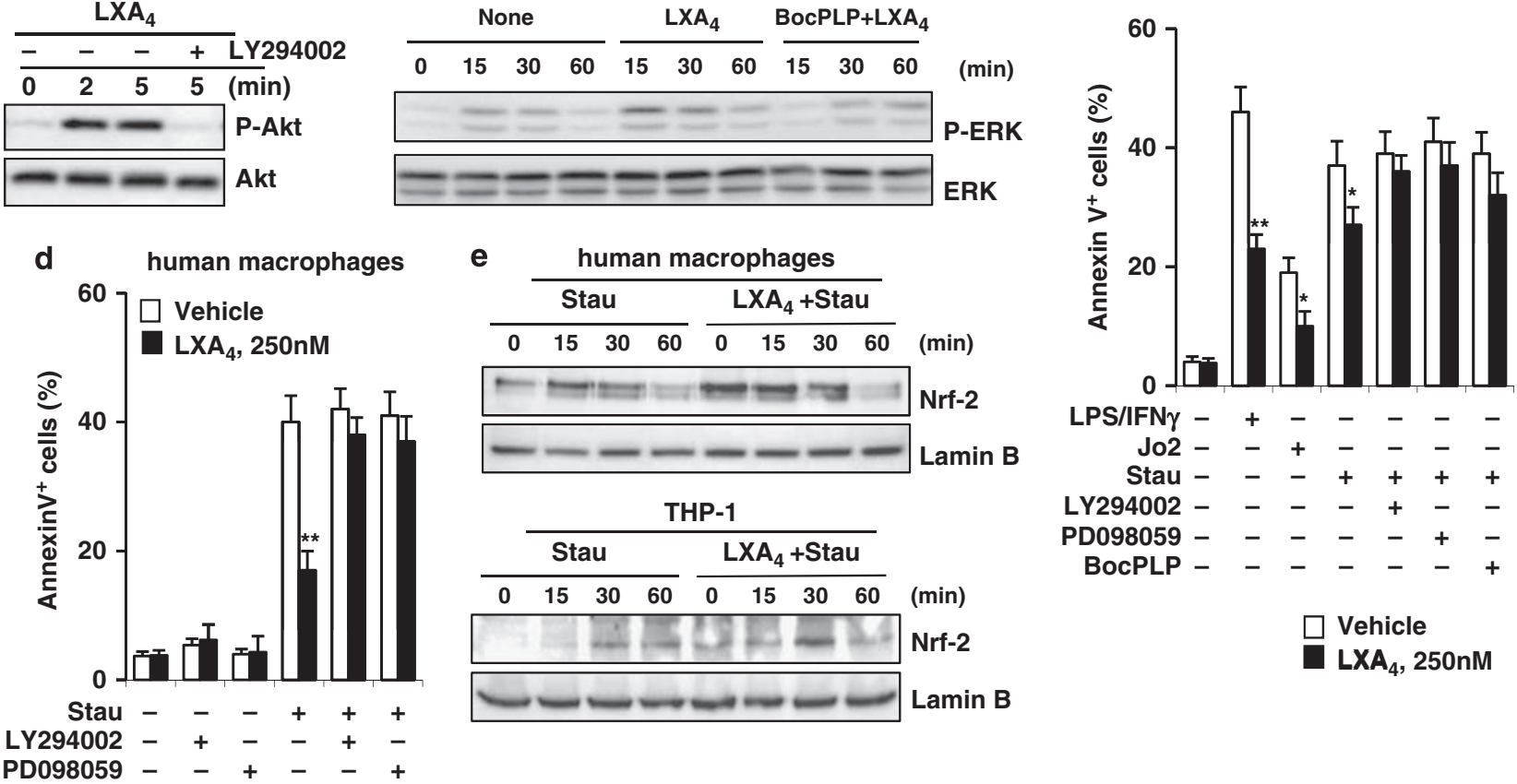

Figure $6 \mathrm{LXA}_{4}$ attenuates apoptosis in peritoneal murine macrophages and in human monocyte/macrophages. Primary cultures of murine peritoneal macrophages (a-c), human peripheral blood monocytes (d, e-left) and the human monocytic cell line THP-1 (e-right) were incubated as indicated. When cells were treated with PD098059 ( $1 \mu \mathrm{M})$ or LY294002 $(10 \mu \mathrm{M})$, addition was $30 \mathrm{~min}$ before $\mathrm{LXA}_{4}$ challenge (a,c and d). When Jo2 $(1 \mu \mathrm{g} / \mathrm{ml})$ was used, cells were incubated for $24 \mathrm{~h}(\mathbf{c})$ BocPLP $(1 \mu \mathrm{M})$ was added $1 \mathrm{~h}$ before lipoxin treatment (b and $\mathbf{c}$ ). Nrf-2 was determined by western blot analysis using nuclear extracts of peripheral blood human monocytes or THP-1 cells (e). Results show the mean \pm S.D. values of four different preparations of cells. ${ }^{*} P<0.05 ;{ }^{*} P<0.01$ versus the corresponding condition in the absence of lipoxin

preventing mitochondrial dysfunction. ${ }^{27}$ In contrast to neutrophils, macrophages arrive later to the inflamed area and they contribute to tissue clearance. Thus, our results indicate that as far as the synthesis of LXs in concerned they act as antiapoptotic molecules, preserving the macrophage function during resolution.

We previously described that the release of NO by activated macrophages contributes transiently to expand macrophage viability by inhibiting caspase processing and activation through the formation of $S$-nitrosothiols in these enzymes. ${ }^{28}$ In line with this, results reported in this study stand directly on the mechanism of action of $L X$ in the resolution of inflammation. The data show that pretreatment of macrophages with LX diminishes staurosporine-, etoposide-, GSNO- and LPS/ IFN $\gamma$-induced apoptosis. Moreover, in murine peritoneal macrophages and in human monocyte/macrophages that exhibit an apoptotic response through the Fas/FasL pathway, treatment with $\mathrm{LXA}_{4}$ also exhibited a protective effect. The fact that the protective effect of $\mathrm{LXA}_{4}$ against apoptosis was observed in human and murine primary cultures of macrophages and in macrophage cell lines suggests the existence of common mechanisms of response to LXs in these cells. The action of $L X$ was independent of the time of pretreatment, from $12 \mathrm{~h}$ to $30 \mathrm{~min}$, before staurosporine challenge (data not shown). These data suggest that the mechanisms involved in protection against apoptosis are mainly regulated by short-term responses to $L X s$, rather than by profound changes in the expression of genes that regulate cell viability.
The apoptosis induced by staurosporine involves essentially the mitochondrial pathway. ${ }^{14,29}$ Activation of apoptosisrelated proteins is considered a basic step in the apoptotic progression, being fundamental to those of the Bcl-2 family that includes both anti- and pro-apoptotic members and other related proteins. Using microarrays of apoptosis-related genes, it was observed that $L X A_{4}$ fails to promote changes in the expression of these genes. However, in the presence of $\mathrm{LX}$ the protein levels of $\mathrm{Bcl}-2, \mathrm{X}-\mathrm{IAP}$ and $\mathrm{Mcl}-1$, all antiapoptotic proteins, were maintained, indicating posttranscriptional regulation. Moreover, our data show that incubation of macrophages with $\mathrm{LXA}_{4}$ promotes a rapid activation of the PI3K/Akt pathway that has a relevant role in the inhibition of apoptosis. ${ }^{30}$ Among the antiapoptotic genes regulated through this pathway, upregulation of $\mathrm{Mcl}-1$ levels have been identified in various cell types, ${ }^{17,18}$ a situation also prevailing in macrophages treated with $\mathrm{LXA}_{4}$. Indeed, incubation with $L X$ preserved the mitochondrial integrity as deduced by the minimal release of cytochrome $c$ and AIF to the cytosol. Oxidative stress is another determinant that regulates the balance between viability/apoptosis. ${ }^{31-33} \mathrm{We}$ have analyzed the effect of $L X$ on the liberation of some important reactive oxygen species (ROS) and reactive nitrogen intermediates (RNIs), using fluorescent probes. Our results indicate that $L X$ inhibits $R O S$ and $R N I$ release, reducing the oxidative stress associated with apoptosis. Consistent with this, treatment with $L X$ at nanomolar concentrations also diminishes the caspase activation induced after staurosporine treatment. This inhibitory action 
was detected for all caspases analyzed, being the most potent effect on caspase 3 and to a lesser extent on both caspase 8 and 9. Results from experiments using the pan-caspase inhibitor z-VAD confirmed the importance of $L X$ reduction of caspase activation, leading to similar levels of apoptosis in macrophages.

In addition to this, it is known that macrophage apoptosis is controlled by a complex network of signaling pathways, including MAPK pathways. ${ }^{32,34,35}$ This study provides evidence that $L X$ might affect these pathways. Incubation of macrophages with staurosporine induces a rapid activation of JNK and p38 MAPKs, but not of ERK, a classic survival pathway. ${ }^{36}$ Interestingly, pretreatment with $L X$ was able to promote ERK phosphorylation in the presence of staurosporine without affecting either JNK or p38 activities. Furthermore, MAPK pathway associates with the modulation of antioxidant response element (ARE)-driven gene expression through Nrf-2 activation, a transcription factor that is considered as the 'guardian of redox homeostasis'. It has been reported that ERK activation is involved in the translocation of Nrf-2 to the nucleus where this transcription factor binds to the ARE motifs. ${ }^{20,37} \mathrm{Nrf}-2$ regulates the transcription of $c a .100$ genes involved in cytoprotection and regulation of oxidative stress. ${ }^{17}$ Recently, it has been described that the $L_{X A_{4}}$-dependent apoptosis of human neutrophils involves the inhibition of myeloperoxidase-induced ERK, which results in a reduction in the expression of the antiapoptotic gene $\mathrm{Mcl}-1 .^{38}$ However, our results provide a new mechanism by which LX impairs macrophage apoptosis, involving Nrf-2 activation through an ERK-dependent pathway. ${ }^{19,20}$

Although multiple studies exist regarding the regulation of innate immunity by LXs, including SOCS2-dependent ubiquitinylation of TRAF-2 and $-6,{ }^{39,40}$ our results demonstrate that $\mathrm{LXA}_{4}$ prolongs macrophages survival by: (a) activation of the PI3K/Akt pathway, leading to the expression of antiapoptotic proteins of the Bcl-2 family; (b) activation of the ERK/Nrf-2 pathway upon challenge with an apoptotic stimulus, such as staurosporine; (c) preservation of mitochondrial function and integrity and enhancement of the antioxidant defense systems in cells; (d) impairment of caspase activation caused by the absence of pro-apoptotic signaling dependent on the mitochondrial pathway or the death-receptor pathway. Therefore, these observations provide an additional antiapoptotic mechanism for $\mathrm{LXA}_{4}$ in macrophages and might contribute to the establishment of a hitherto unrecognized potential of LXs for the treatment of inflammatory diseases.

\footnotetext{
Materials and Methods

Materials. Staurosporine, MG132, LY294002 and PD098059 were purchased from Calbiochem (San Diego, CA, USA); $\mathrm{LXA}_{4}$ and 15-epi-LXA ${ }_{4}$ were purchased from Cayman (Ann Arbor, MI, USA) or Calbiochem; etoposide, LPS, PMA and GSNO were from Sigma (St. Louis, MO, USA); IFN $\gamma$ was obtained from PeproTech (London, UK)); Jo2 was purchased from BD (San Jose, CA, USA). N-t-Boc-PheLeu-Phe-Leu-Phe (BocPLP), a formyl peptide LX receptor-competitive antagonist was obtained from Bachem (Bubendorf, $\mathrm{CH}$; Switzerland); antibodies were purchased from Santa Cruz Biotechnology (Santa Cruz, CA, USA), BD Transduction Laboratories or Cell Signaling Technology (Danvers, MA, USA). Fluorescent probes were obtained from Molecular Probes (Eugene, OR, USA). Other reagents were from purchased Roche (Mannheim, Germany) or Sigma. Tissue culture dishes were purchased from Falcon (Lincoln Park, NJ, USA) and culture media were obtained from Invitrogen (Carlsbad, CA, USA).
}

Animals. The 7-week-old male wild-type C57BL/6 mice and nrf-2-knockout littermates were a generous gift from $\mathrm{Dr}$ A Cuadrado (IIBM, Madrid). Mice were housed at RT under 12-h light/dark cycle, and food and water were provided ad libitum. Animals were cared for according to a protocol approved by the Ethics Committee of our institution (following 86/609/EEC, 2003/65/EC directives).

Isolation of human monocytes. The PBMCs were isolated from blood of healthy donors by centrifugation on Ficoll-Hypaque Plus (GE Healthcare, Barcelona, Spain) following the manufacturers' protocol. Cells were maintained for $2 \mathrm{~h}$ at a density of $10^{6}$ cells per $\mathrm{ml}$ in DMEM supplemented with antibiotics (100 IU/ml penicillin and $100 \mu \mathrm{g} / \mathrm{ml}$ streptomycin). After this period, the supernatant was removed and adherent cells were cultured in the same medium supplemented with $10 \%$ heat-inactivated FBS. Purity of all cultures was verified by $\mathrm{CD} 14^{+}$ staining; on average $87 \%$ of the cells presented this surface marker. Cells were maintained overnight with this medium and differentiated with h-MCSF $(20 \mathrm{ng} / \mathrm{ml}$, PeproTech) for 7 days followed by treatment with the indicated stimuli.

Cell culture and transient transfections. The macrophage cell line RAW 264.7 was maintained in RPMI 1640 medium containing $100 \mathrm{U} / \mathrm{ml}$ penicillin, $100 \mu \mathrm{g} / \mathrm{ml}$ streptomycin and $10 \%$ heat-inactivated FBS. Before experiments were conducted, the medium was challenged with $1 \%$ FBS. Elicited peritoneal macrophages were prepared as previously described ${ }^{21}$ and used as indicated for the cell line. For transient transfections, cells were grown at $80 \%$ confluence and transfected using the Cell Line Nucleofector Kit V following the manufacturer's instructions (Amaxa, Cologne, Germany). After nucleofection, cells were stimulated for $6 \mathrm{~h}$ and luciferase activity was measured using a Dual Luciferase Reporter Assay System (Promega, Madrid, Spain). The human monocytic THP-1 cells were maintained in culture with RPMI 1640 supplemented with $10 \%$ FBS and $20 \mathrm{mM}$ HEPES. For the induction of differentiation of THP-1 monocytes into macrophages PMA $(50 \mathrm{nM}, 48 \mathrm{~h})$ was used. Then, the medium was changed to RPMI 1640 supplemented with $1 \%$ FBS and cells were stimulated for the indicated periods of time.

Preparation of total protein cell extracts. Cells were homogenized in a medium containing $10 \mathrm{mM}$ Tris- $\mathrm{HCl}(\mathrm{pH} 7.5), 1 \mathrm{mM} \mathrm{MgCl}, 1 \mathrm{mM}$ EGTA, $10 \%$ glycerol, $0.5 \%$ CHAPS, $1 \mathrm{mM} \beta$-mercaptoethanol and $0.1 \mathrm{mM}$ PMSF and a protease and phosphatase inhibitor cocktail (Sigma). The extracts were vortexed for $30 \mathrm{~min}$ at $4^{\circ} \mathrm{C}$ and after centrifuging for $20 \mathrm{~min}$ at $13000 \times g$ the supernatants were stored at $20^{\circ} \mathrm{C}$. Protein levels were determined using Bradford reagent (Bio-Rad, Hercules, CA, USA).

Preparation of cytosolic and nuclear protein cell extracts. Stimulated cells were collected into ice-cold PBS, resuspended in $200 \mu$ l of cytosolic buffer (10 mM HEPES (pH 8), $10 \mathrm{mM} \mathrm{KCl,} 1 \mathrm{mM}$ EDTA, $1 \mathrm{mM}$ EGTA and $0.5 \% \mathrm{NP}$ 40) and left to swell on ice for $15 \mathrm{~min}$. Cells were vortexed and centrifuged at $12000 \times g$ for $30 \mathrm{~s}$. The pellet was resuspended in $50 \mu$ of ice-cold nuclear buffer (20 mM HEPES (pH 8), $0.4 \mathrm{M} \mathrm{NaCl}, 1 \mathrm{mM}$ EDTA, $1 \mathrm{mM}$ EGTA and 20\% glycerol) and vortexed at $4{ }^{\circ} \mathrm{C}$ for $30 \mathrm{~min}$. After centrifugation $\left(12000 \times \mathrm{g}\right.$ at $4{ }^{\circ} \mathrm{C}$ for $\left.20 \mathrm{~min}\right)$, the supernatant was transferred to a fresh tube. All buffers contained protease and phosphatase inhibitor cocktail (Sigma).

Cytochrome $c$ release assay. Cell pellets were resuspended in buffer $A$ $(0.32 \mathrm{M}$ sucrose, $10 \mathrm{mM}$ Tris- $\mathrm{HCl}, 1 \mathrm{mM}$ EDTA $(\mathrm{pH} 7.5)$ and protease inhibitor cocktail) and homogenized by repeated passage through a $27-G$ needle. Then cells were centrifuged for $15 \mathrm{~min}$ at $4{ }^{\circ} \mathrm{C}$ and $10000 \times \mathrm{g}$. The supernatants were saved as cytosolic fractions and stored at $-80^{\circ} \mathrm{C}$. Pellets were resuspended again in buffer A and were saved as 'particulate' fractions containing mitochondria and stored at $-80^{\circ} \mathrm{C}$ until cytochrome $c$ quantification.

Western blot analysis. Equal amounts of protein $(20-50 \mu \mathrm{g})$ from each fraction obtained were loaded onto a 10-12\% SDS-PAGE gel. Proteins were size fractionated, transferred to a Hybond-P membrane (GE Healthcare) and, after blocking with $5 \%$ nonfat dry milk, incubated with the corresponding Abs. The blots were developed by ECL protocol (GE Healthcare) and different exposition times were performed for each blot with a Charged Coupling Device camera in a luminescent image analyzer (Molecular Imager, Bio-Rad) to ensure the linearity of the band intensities. Values of densitometry were determined using Quantity One software (Bio-Rad). 
In vitro and in vivo caspase activity assays. For the in vitro determination, total cell extracts were prepared and supernatants were used to measure caspase activities by cleavage of specific substrates in accordance with the supplier's instruction (BD, Pharmingen). Caspase activity was quantified fluorimetrically by following the cleavage of Ac-DEVD-AMC for caspase 3, Ac-IETD-AFC for caspase 8 and Ac-Leu-Glu-His-Asp-AFC for caspase 9. Cell lysates were incubated for 60 min at RT with corresponding substrates and the activity was measured with excitation-emission wavelengths of $340-460 \mathrm{~nm}$ for caspase 3 and $400-480$ for caspase 8 and 9. CaspGLOW fluorescein Active Caspases Staining kit was also used to detect activated caspases in living cells by fluorescence microscopy, according to manufacturer instructions (Biovision Res, Mountain View, CA, USA). Briefly, cells were treated with the indicated stimuli and incubated in the presence of a fluorescent marker conjugated to FITC that irreversibly binds to activated caspases in apoptotic cells. This label allows for the direct detection of apoptotic cells by fluorescence microscopy.

Flow cytometry. Analysis was carried out using a FC 500 Becton Dickinson FACScan flow cytometer (Mountain View, CA, USA) using a CXP Software (Beckman Coulter, Brea, CA, USA).

Cell death detection. Cells were collected and washed in cold PBS. After centrifugation at $4^{\circ} \mathrm{C}$ for $5 \mathrm{~min}$ and $1000 \times \mathrm{g}$, cells were resuspended in annexin V-binding buffer (10 mM HEPES (pH 7.4), $140 \mathrm{mM} \mathrm{NaCl}$ and $2.5 \mathrm{mM} \mathrm{CaCl}_{2}$ ). Cells were labeled with annexin V-FITC solution (BD Pharmingen) and propidium iodide (PI) $(100 \mu \mathrm{g} / \mathrm{ml})$ for $15 \mathrm{~min}$ at RT in the dark. The percentage of cells with hyplodiploid DNA was used as another marker of apoptosis. For DNA detection, cells were suspended in $0.5 \mathrm{ml}$ of $100 \mu \mathrm{g} / \mathrm{ml} \mathrm{PI}$ in $0.1 \%$ sodium citrate plus $0.1 \%$ Triton X-100.

Immunofluorescence microscopy. The RAW 264.7 cells were seeded into sterile 8-well Chamber Slides (Falcon) at $16-24 \mathrm{~h}$ before treatment. MitoTraker Red CMXRos ( $50 \mathrm{nM}$, Molecular Probes) was added to the culture medium for $30 \mathrm{~min}$ before washing cells with PBS followed by fixation with $2 \%$ paraformaldehyde for $10 \mathrm{~min}$. Cells were then permeabilized in ice-cold methanol and incubated with $3 \% \mathrm{BSA}$ for $30 \mathrm{~min}$. After incubating with a rabbit Ab against AIF (Santa Cruz Biotechnology) at $4^{\circ} \mathrm{C}$ for $1 \mathrm{~h}$, cells were washed with PBS followed by incubating with Alexa 488 anti-rabbit secondary antibody at $4^{\circ} \mathrm{C}$ for $1 \mathrm{~h}$ at $\mathrm{RT}$ (1:500 Molecular Probes). Coverslips were mounted in Vectashield (Vector Laboratories, Burlingame, CA, USA) and examined using an Espectral Leica TCS SP5 confocal microscope. Values of intensity fluorescence and co-localization quantification were performed using Image J software (NIH, Bethesda, MD, USA).

ROS and RNI determination. Generation of ROS in RAW 264.7 cells was analyzed by flow cytometry monitoring the oxidation of $2^{\prime}, 7^{\prime}$-dichlorodihydrofluorescein (DCFH). Cells were loaded with $0.4 \mu \mathrm{M} \mathrm{DCFH}$ for $30 \mathrm{~min}$, pelleted and resuspended in PBS followed by flow cytometry. Synthesis of RNI was determined by incubating cells with $200 \mu \mathrm{M}$ DAF-2 diacetate.

Microarray analysis of apoptosis-related genes. Total RNA was isolated from cells using TRIzol Reagent (Invitrogen) and further cleaned up using the Qiagen RNeasy MiniKit (Hilden, Germany) with one step of DNAse I digestion. A total of $3 \mu \mathrm{g}$ of RNA were used for CDNA synthesis with $\mathrm{RT}_{2}$ first Standard kit (SuperArray Bioscience, Frederick, MD, USA). The mouse apoptosis PCR array was performed according to the manufacturer's protocol using the Profiler PCR Array System and the SYBR Green/Fluorescein qPCR master mix (SuperArray Bioscience) on a MyiQ Real-Time PCR System (Bio-Rad). Gene expression was compared with the web-based software package for the PCR Array System (http://www.superarray.com/pcr/arrayanalysis.php). This software automatically

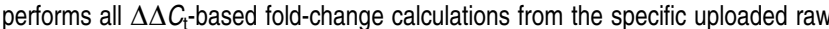
threshold cycle data. Results were analyzed as described by Mayoral et $\mathrm{al}^{22}$ and RT-PCR of selected genes was used to validate the microarray data.

Statistical analysis. The values in graphs correspond to mean \pm S.D values. The statistical significance was estimated with a Student $t$-test for unpaired observation. Data were analyzed using the SPSS (Madrid, Spain) for Windows statistical package, version 9.0.1.
Acknowledgements. PP was supported by a fellowship from Ministerio de Ciencia e Innovación (MICINN; Spain). This work was supported by grant BFU200802161 from MICINN, S-BIO-0283/2006 from Comunidad de Madrid and FIS-RECAVA RD06/0014/0025. RECAVA and Ciberehd are funded by the Instituto de Salud Carlos III.

1. Levy BD, Clish CB, Schmidt B, Gronert K, Serhan $C N$. Lipid mediator class switching during acute inflammation: signals in resolution. Nat Immunol 2001; 2: 612-619.

2. Serhan CN, Savill J. Resolution of inflammation: the beginning programs the end. Nat Immunol 2005; 6: 1191-1197.

3. Kennedy AD, Deleo FR. Neutrophil apoptosis and the resolution of infection. Immunol Res 2008; 43: 25-61.

4. Serhan $\mathrm{CN}$, Chiang N, Van Dyke TE. Resolving inflammation: dual anti-inflammatory and pro-resolution lipid mediators. Nat Rev Immunol 2008; 8: 349-361.

5. McMahon B, Mitchell S, Brady HR, Godson C. Lipoxins: revelations on resolution. Trends Pharmacol Sci 2001; 22: 391-395.

6. Serhan CN. Lipoxins and aspirin-triggered 15-epi-lipoxins are the first lipid mediators of endogenous anti-inflammation and resolution. Prostaglandins Leukot Essent Fatty Acids 2005; 73: 141-162.

7. Godson C, Mitchell S, Harvey K, Petasis NA, Hogg N, Brady HR. Cutting edge: lipoxins rapidly stimulate nonphlogistic phagocytosis of apoptotic neutrophils by monocyte-derived macrophages. J Immunol 2000; 164: 1663-1667.

8. Chen M, Divangahi M, Gan H, Shin DS, Hong S, Lee DM et al. Lipid mediators in innate immunity against tuberculosis: opposing roles of PGE2 and LXA4 in the induction of macrophage death. J Exp Med 2008; 205: 2791-2801.

9. Serhan CN, Brain SD, Buckley CD, Gilroy DW, Haslett C, O'Neill LA et al. Resolution of inflammation: state of the art, definitions and terms. FASEB J 2007; 21: 325-332.

10. Wu SH, Lu C, Dong L, Zhou GP, He ZG, Chen ZQ. High dose of lipoxin A4 induces apoptosis in rat renal interstitial fibroblasts. Prostaglandins Leukot Essent Fatty Acids 2005; 73: 127-137.

11. Jozsef L, Zouki C, Petasis NA, Serhan CN, Filep JG. Lipoxin A4 and aspirin-triggered 15-epi-lipoxin A4 inhibit peroxynitrite formation, NF-kappa B and AP-1 activation, and IL-8 gene expression in human leukocytes. Proc Natl Acad Sci USA 2002; 99: 13266-13271.

12. Goh J, Baird AW, O'Keane C, Watson RW, Cottell D, Bernasconi G et al. Lipoxin A(4) and aspirin-triggered 15-epi-lipoxin $\mathrm{A}(4)$ antagonize TNF-alpha-stimulated neutrophilenterocyte interactions in vitro and attenuate TNF-alpha-induced chemokine release and colonocyte apoptosis in human intestinal mucosa ex vivo. J Immunol 2001; 167 : 2772-2780.

13. Calandria JM, Marcheselli VL, Mukherjee PK, Uddin J, Winkler JW, Petasis NA et al. Selective survival rescue in 15-lipoxygenase-1-deficient retinal pigment epithelial cells by the novel docosahexaenoic acid-derived mediator, neuroprotectin D1. J Biol Chem 2009; 284: 17877-17882

14. Zhang XD, Gillespie SK, Hersey P. Staurosporine induces apoptosis of melanoma by both caspase-dependent and -independent apoptotic pathways. Mol Cancer Ther 2004; 3 : 187-197.

15. Bosca L, Hortelano S. Mechanisms of nitric oxide-dependent apoptosis: involvement of mitochondrial mediators. Cell Signal 1999; 11: 239-244.

16. Morel C, Carlson SM, White FM, Davis RJ. Mcl-1 integrates the opposing actions of signaling pathways that mediate survival and apoptosis. Mol Cell Biol 2009; 29: 3845-3852.

17. Hayes JD, McMahon M. NRF2 and KEAP1 mutations: permanent activation of an adaptive response in cancer. Trends Biochem Sci 2009; 34: 176-188.

18. Nguyen $T$, Nioi $P$, Pickett $C B$. The Nrf2-antioxidant response element signaling pathway and its activation by oxidative stress. J Biol Chem 2009; 284: 13291-13295.

19. Zipper LM, Mulcahy RT. Inhibition of ERK and p38 MAP kinases inhibits binding of Nrf2 and induction of GCS genes. Biochem Biophys Res Commun 2000; 278: 484-492.

20. Yu R, Chen C, Mo YY, Hebbar V, Owuor ED, Tan TH et al. Activation of mitogen-activated protein kinase pathways induces antioxidant response element-mediated gene expression via a Nrf2-dependent mechanism. J Biol Chem 2000; 275: 39907-39913.

21. de las Heras B, Hortelano S, Giron N, Bermejo P, Rodriguez B, Bosca L. Kaurane diterpenes protect against apoptosis and inhibition of phagocytosis in activated macrophages. Br J Pharmacol 2007; 152: 249-255.

22. Mayoral R, Molla B, Flores JM, Bosca L, Casado M, Martin-Sanz P. Constitutive expression of cyclo-oxygenase 2 transgene in hepatocytes protects against liver injury. Biochem J 2008; 416: 337-346.

23. Perretti M, D'Acquisto F. Annexin A1 and glucocorticoids as effectors of the resolution of inflammation. Nat Rev Immunol 2009; 9: 62-70.

24. Maderna $\mathrm{P}$, Godson $\mathrm{C}$. Taking insult from injury: lipoxins and lipoxin receptor agonists and phagocytosis of apoptotic cells. Prostaglandins Leukot Essent Fatty Acids 2005; 73: 179-187.

25. Bailey DP, Kashyap M, Bouton LA, Murray PJ, Ryan JJ. Interleukin-10 induces apoptosis in developing mast cells and macrophages. J Leukoc Biol 2006; 80: 581-589. 
26. Serhan CN, Yacoubian S, Yang R. Anti-inflammatory and proresolving lipid mediators. Annu Rev Pathol 2008; 3: 279-312.

27. Chiang N, Serhan CN, Dahlen SE, Drazen JM, Hay DW, Rovati GE et al. The lipoxin receptor ALX: potent ligand-specific and stereoselective actions in vivo. Pharmacol Rev 2006; 58: 463-487.

28. Hortelano S, Traves PG, Zeini M, Alvarez AM, Bosca L. Sustained nitric oxide delivery delays nitric oxide-dependent apoptosis in macrophages: contribution to the physiological function of activated macrophages. J Immunol 2003; 171: 6059-6064.

29. Yamaki K, Hong J, Hiraizumi K, Ahn JW, Zee O, Ohuchi K. Participation of various kinases in staurosporine induced apoptosis of RAW 264.7 cells. J Pharm Pharmacol 2002; 54 1535-1544.

30. Parcellier A, Tintignac LA, Zhuravleva E, Hemmings BA. PKB and the mitochondria: AKTing on apoptosis. Cell Signal 2008; 20: 21-30

31. Fialkow L, Wang Y, Downey GP. Reactive oxygen and nitrogen species as signaling molecules regulating neutrophil function. Free Radic Biol Med 2007; 42: 153-164.

32. Noguchi T, Ishii K, Fukutomi H, Naguro I, Matsuzawa A, Takeda $\mathrm{K}$ et al. Requirement of reactive oxygen species-dependent activation of ASK1-p38 MAPK pathway for extracellular ATP-induced apoptosis in macrophage. J Biol Chem 2008; 283: $7657-7665$.

33. Owuor ED, Kong AN. Antioxidants and oxidants regulated signal transduction pathways. Biochem Pharmacol 2002; 64: 765-770.
34. Ewings KE, Hadfield-Moorhouse K, Wiggins CM, Wickenden JA, Balmanno K, Gilley R et al. ERK1/2-dependent phosphorylation of BimEL promotes its rapid dissociation from Mcl-1 and Bcl-XL. EMBO J 2007; 26: 2856-2867.

35. Monick MM, Powers LS, Barrett CW, Hinde S, Ashare A, Groskreutz DJ et al. Constitutive ERK MAPK activity regulates macrophage ATP production and mitochondrial integrity J Immunol 2008; 180: 7485-7496.

36. Sabbagh L, Pulle G, Liu Y, Tsitsikov EN, Watts TH. ERK-dependent Bim modulation downstream of the 4-1BB-TRAF1 signaling axis is a critical mediator of CD8T cell survival in vivo. J Immunol 2008; 180: 8093-8101.

37. Kang KA, Lee KH, Park JW, Lee NH, Na HK, Surh YJ et al. Triphlorethol-A induces heme oxygenase-1 via activation of ERK and NF-E2 related factor 2 transcription factor. FEBS Lett 2007; 581: 2000-2008.

38. El Kebir D, Jozsef L, Pan W, Wang L, Petasis NA, Serhan CN et al. 15-epi-lipoxin A4 Inhibits Myeloperoxidase Signaling and Enhances Resolution of Acute Lung Injury. Am J Respir Crit Care Med 2009; 180: 311-319.

39. Machado FS, Esper L, Dias A, Madan R, Gu Y, Hildeman D et al. Native and aspirintriggered lipoxins control innate immunity by inducing proteasomal degradation of TRAF6. J Exp Med 2008; 205: 1077-1086.

40. Machado FS, Johndrow JE, Esper L, Dias A, Bafica A, Serhan CN et al. Anti-inflammatory actions of lipoxin A4 and aspirin-triggered lipoxin are SOCS-2 dependent. Nat Med 2006 12: $330-334$. 